\title{
Estimation of leakage from the freshwater network in Kuwait
}

\author{
A. Al-Khalid, M. Al-Senafy \& E. Azrag \\ Hydrology Department, Water Resources Division, \\ Kuwait Institute for Scientific Research, Kuwait
}

\begin{abstract}
The objective of this paper is to assess the extent of fresh water leakage loss in Kuwait and to recommend to the Ministry of Electricity and Water (MEW) the steps to be taken for the minimization of this loss. A broad conclusion was made from the study that water loss through real leakage is not a significant problem in the Kuwait water distribution system; however, more improvements can be made to reduce the non-revenue water loss. A preliminary system water balance has been carried out using available reported data. This water balance indicated that the real loss in the system is about $5 \%$. An attempt was carried out to validate leakage levels by investigating night flows and water balances on six DMAs namely, Al-Sha'ab, Al-Rihab, Al-Qadsiya, Al-Riggae, Al-Shuhada and AlHadiya. Based on the national average of real losses normalized by the ratio of the local mass balance discrepancy to the national average, the estimates of real loss (leakage) ranged from $1-12 \%$ where as the non revenue water could reach close to half of the fresh water input. More detailed field leakage detection surveys and pressure drop tests were carried out on each DMA. The field leakage detection survey indicated that there was little detectable real leakage except for Al-Qadsiya DMA. Almost all the leakages found were at the consumer connection. During the investigation a number of issues were found related to customer metering such as poor installation details, pumps on the supply pipe affecting meter readings, and damaged meters. The combined effect of these issues means that there could be significant meter under registration in the range of $10-50 \%$. Recommendations are made to reduce the amount of non-revenuewater (including real losses), to improve the distribution network in general. The most important recommendation is to investigate and improve the materials and the practice of installing consumers' connections as it is the main source of real
\end{abstract}


leakage. The problem of meter under-registration has to be effectively resolved to reduce the non revenue percentage of potable water and to increase the accuracy of future leakage monitoring.

Keywords: management, water loss, water balance, night flows.

\section{Introduction}

The demand of potable water almost entirely supplied by the seawater desalination plants is increasing and by far outpacing the rate of increase in the population is an undeniable fact in Kuwait. The demand for potable water increased steeply in the recent years from $194 \mathrm{Mm}^{3} / \mathrm{y}$ in 1992 to $610 \mathrm{Mm}^{3} / \mathrm{y}$ in 2011 [1]. This fact leaves no room for ignoring any loss in the supplied potable water, no matter how small. Knowing the absolute magnitude and the relative percentage of the loss is a very important guideline in setting priorities on development and rehabilitation of the potable water future production and delivery system, respectively. The minimization of loss from the freshwater network through leakage is one of the ways to conserve the costly resource. Identification of the leakages in the network and estimation of losses through these leakages that may be currently taking place, is the first step towards devising ways to control this loss.

The present document has been prepared for the ministry by KISR and their consultants to document the results of the investigations on the level of leakage within Kuwait. The non-revenue-water (NRW) analysis has been commissioned as part of a larger study carried out by KISR and HydroSave International Ltd., UK to evaluate real leakage levels, and to determine appropriate leakage detection techniques.

The main objectives of the study, as specified by the initial request from MEW were to detect the leakages in the network and to estimate the extent of losses through leakage in the pilot areas.

\section{Methodology}

The steps taken to achieve the aforementioned objectives were set in the following activities:

a) Selection of representative District Metered Areas (DMA),

b) Calculating the water balance for the whole system and on each DMA, and

c) Implementing a leakage detection field survey.

The pilot areas were selected to represent different demography and building types of Kuwait. Eight discrete DMAs were selected for this purpose and they are as follows:

Al-Qadsiya;

Al-Shuhada;

Al-Shuwaikh (B) residential;

Al-Riggae;

Al-Nuzha; 


\author{
Al-Rihab; \\ Al-Sha'ab Coastal Area (Al-Sahili); \\ Al-Hadiya.
}

Fig. 1 shows the distribution of the selected DMAs over Kuwait. Maps of the network and pertinent data on the population were collected from the Network Management Department of MEW [2].

The standard IWA water balance approach and methodology has been used to assess the real and apparent losses from the distribution system. An estimate of the confidence level of the assessment has also been included. In addition, the standard IWA performance measures and infrastructure leakage index was also assessed [3].

A key piece of information that was not available is the authorized volume (billed and unbilled). In the absence of this information, the consumption has been estimated by combining an estimated per capita consumption (PCC) with the stated population. However, the problem arises in establishing a reliable PCC value.

Two types of survey to estimate a PCC were conducted. The first consumption survey was carried out manually by reading the meters in a number of residential premises over a short period of time (four to seven days). Over six hundred residents were surveyed in five DMAs of the pilot study areas. In the second consumption survey, more extensive flow-meter readings in a number of premises were collected and logged with time intervals (every half an hour) for a period of seven days using a snap-shot camera device in an attempt to establish the PCC and the minimum night flow per capita or per property.

The non-household consumption was assumed a value of $15 \%$ of total water production. This includes tanker water, which contributed 10 to $12 \%$ of the total consumption [4] and other non-household consumption i.e., industrial and commercial.

The unbilled authorized consumption was extracted from MEW to be $80 \mathrm{Ml} / \mathrm{d}$ in the year 2005, which represented the summation of $28 \mathrm{Ml} / \mathrm{d}$ used within fresh water production facilities and $52 \mathrm{Ml} / \mathrm{d}$ authorized to be used elsewhere [4].

Unauthorized consumption was estimated to be $1 \%$ in the absence of data to support a more accurate number.

\title{
3 Approach to assessing leakage in DMAs
}

The approach taken was to carry out an assessment of leakage on each DMA by the water balance method and to compare this where possible with an assessment using the night approach. The water balance approach is essentially the same as that carried out at system level except that all the complexities of unbilled use and meter under registration are not normally included. The daily average input volume on the DMA is assessed by measuring the flow through the DMA meters and adding them, or netting them off, as appropriate. The daily consumption is assessed by estimating actual consumption through customer revenue meters. Generally, it would be too large a task to read all the revenue meters on a DMA 
at the same time. So on larger DMAs, meters at a number of representative premises may be read and the total consumption estimated by extrapolation either on the basis of the average consumption premises or an estimate of the consumption per head PCC. The latter relies on an estimate or establishment of the number of occupants in premises at the time of the survey. The difference between the input volume and the assessed consumption is normally taken to be leakage although strictly it is a non-revenue water, as it will include apparent losses, i.e., meter under registration errors, possible theft, or bypassing of meters etc.

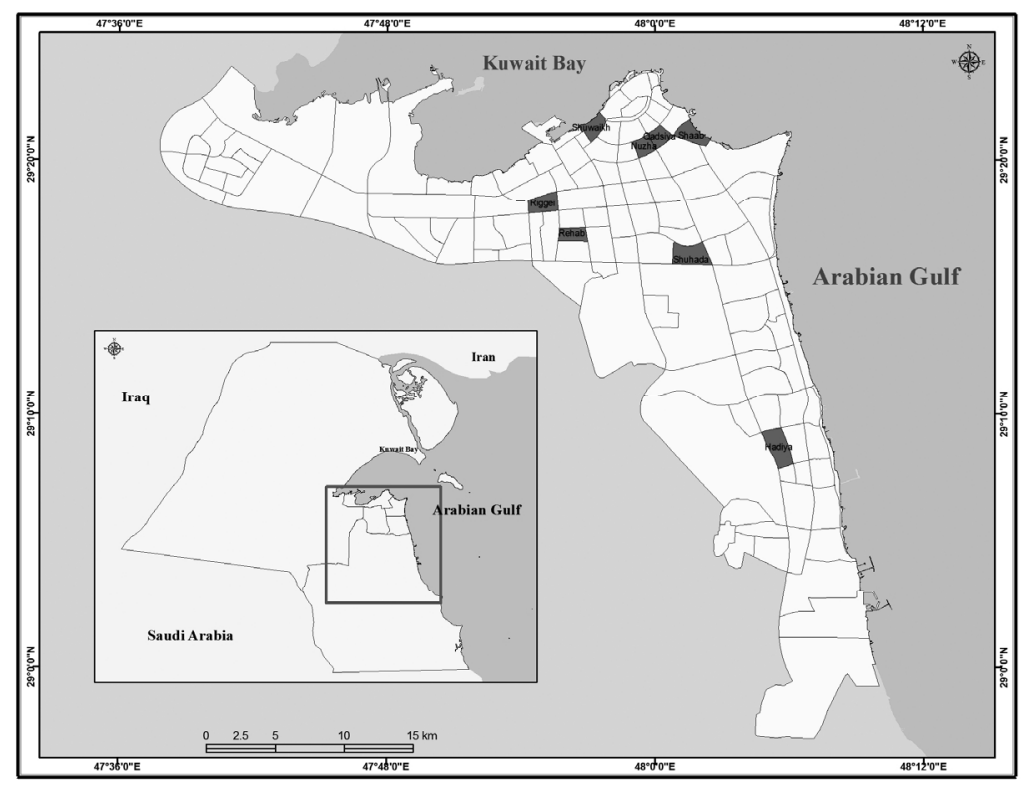

Figure 1: $\quad$ Distribution of selected DMA areas.

The night approach is based on an assumption that during the night there will be a period when there will be a low level of actual usage and a major fraction of the flow can be assumed to be leakage. This technique is used extensively in the UK when low flows generally occurred between 3:00 a.m. and 4:00 a.m.

Little work has been carried out in Kuwait to establish typical night use values. The snap shot camera exercise did allow the abstraction of night use since readings were taken about every $30 \mathrm{~min}$. for a number of days. This data was abstracted and analyzed.

The estimates of losses by the two methods (water balance and night) should compare closely. If there is a significant difference (e.g., $>5 \%$ ) then it would normally indicate errors in the estimates of one or more of the components.

A check was carried out to confirm that the comparison stands up at the basic level. This check involves assuming that the minimum night flow is all losses (pessimistic as there will be some legitimate use) and assuming that these losses 
occur at the same rate throughout the day. Again, this is pessimistic as it is more likely that losses will be lower during the day when pressures are lower. This assessed volume is subtracted from the total input into the DMA and can be considered to be an estimate of the minimum value in demand. If this minimum demand is lower than the assessed demand then the assessment is feasible (though not necessarily accurate) but if it is greater than the assumed demand, then the assessment is infeasible and there must be gross errors in the estimation of demand. The analysis of leakage using two methods presented above was carried out on the following DMAs:

- Al-Sha'ab

- Al-Rihab

- Al-Qadsiya

- Al-Riggae

- Al-Shuhada

- Al-Hadiya

The analysis included estimates of the confidence levels in order to investigate whether the difference of the leakage estimates from the two methods was significant.

\section{Results}

To establish the mass balance estimate in the system as a whole and in individual DMAs the results of household consumption need to be considered first. The flow into a number of premises using a snapshot camera device was analyzed in an attempt to establish the PCC. The results are shown in Table 1

Table 1: $\quad$ Results of PCC study: snapshot meter survey.

\begin{tabular}{lccccc}
\hline Area No. of Premises & $\begin{array}{c}\text { PPC } \\
\text { (l/prop/d) }\end{array}$ & \multicolumn{2}{c}{$\begin{array}{c}\text { No. of } \\
\text { Occupants }\end{array}$} & $\begin{array}{c}\text { PCC } \\
\text { (l/hd/d) }\end{array}$ & $\begin{array}{c}\text { Occupancy } \\
\text { (hd/prop) }\end{array}$ \\
\hline Al-Qadsiya & 43 & 3939 & 502 & 337 & 11.7 \\
Al-Shuwaikh & 15 & 3912 & 123 & 477 & 8.2 \\
Al-Sha'ab & 15 & 13467 & 543 & 372 & 36.2 \\
\hline Weighted Total & 73 & 5891 & 1168 & 368 & 16.0 \\
\hline
\end{tabular}

1/prop/d - liters per property per day; l/hd/d - liter per head per day; hd/prop head per property

Based on this survey and an assumption that predominant housing type in the selected DMA is villa, a PCC of 368 has been taken with a confidence level of $\pm 10 \%$. An improved estimate could be made by stratifying the customer base into a number of housing types and applying different PCCs to produce a housing type weighted average PCC.

The results of the manual survey are shown in Table 2. Occupancy levels were established on two of the areas, one of these areas was also Al-Qadsiya. 
The average PCC was estimated as $323 \mathrm{l} / \mathrm{hd} / \mathrm{d}$. This is close to the PCC established for Al-Qadsiya using the camera technique which gives some confidence to the results.

Table 2: $\quad$ Results of consumption monitoring on DMAs: manual reading survey.

\begin{tabular}{lccccc}
\hline Area & $\begin{array}{c}\text { No. of } \\
\text { Premises }\end{array}$ & $\begin{array}{c}\text { PPC } \\
(\mathrm{l} / \text { prop/d) }\end{array}$ & $\begin{array}{c}\text { No. of } \\
\text { Occupants }\end{array}$ & $\begin{array}{c}\text { PCC } \\
(\mathrm{l} / \mathrm{hd} / \mathrm{d})\end{array}$ & $\begin{array}{c}\text { Occupancy } \\
\text { (hd/prop) }\end{array}$ \\
\hline Al-Qadsiya & 119 & 4095 & 1524 & 320 & 12.8 \\
Al-Rihab & 132 & 2815 & 1138 & 326 & 8.6 \\
Al-Riggae & 91 & 7215 & - & - & - \\
Al-Sha’ab & 86 & 9262 & - & - & - \\
Al-Shuhada & 184 & 2808 & - & - & - \\
\hline
\end{tabular}

The results of the system water balance analysis are summarized in Table 3 . The analysis shows that non-revenue water is estimated to be $276 \mathrm{Ml} / \mathrm{d}$ or $20 \%$ of the System Input Volume with a confidence level of $\pm 68 \%$. Using all the assumptions discussed above for each component of the mass balance the split is assessed as apparent losses of $125 \mathrm{Ml} / \mathrm{d}$ with a confidence level of $\pm 22 \%$, unbilled authorized consumption of $80 \mathrm{Ml} / \mathrm{d}$ with a confidence level of $\pm 2 \%$, and real losses of $71 \mathrm{Ml} / \mathrm{d}$ (15.6 MIG/d) with a confidence level of $260 \%$ which can be interpreted as the real losses can vary from as a low as no losses (zero) to as high as $185 \mathrm{Ml} / \mathrm{d}$ (40.6 MIG/d). The assessment of real losses has a very high uncertainty due to the fact that it is a very low number being the difference between two large numbers, one of which (actual consumption) has high uncertainty.

Table 3: $\quad$ Results of system water balance analysis.

\begin{tabular}{lccc}
\hline Description & Unit & Value & $\begin{array}{c}95 \% \\
\text { Confidence Level }\end{array}$ \\
\hline Non-revenue water & Ml/d & 276 & 68 \\
& \%SIV & 20 & 68 \\
\hline Apparent losses & $\mathrm{Ml} / \mathrm{d}$ & 125 & 22 \\
\hline Real losses & $\mathrm{Ml} / \mathrm{d}$ & 71 & 260 \\
& \%SIV & 5 & 260 \\
& l/conn/d & 549 & 260 \\
& $\mathrm{ILI}$ & 15 & 260 \\
\hline
\end{tabular}

Note: $1 \mathrm{MIG} / \mathrm{d}=4.546 \mathrm{Ml} / \mathrm{d}$ 
Table 4 shows a summary of the results for all the field work and an analysis for the DMA NRW tests. The table shows a wide variation in the figures between DMAs and more noticeably a wide difference in the level of NRW assessed by both techniques. It must be emphasized that the assessment has been carried out without any allowance for meter under registration and is therefore an assessment of total losses and not just real losses (leakage).

It is always difficult to extrapolate results from a small number of DMAs to draw conclusions concerning system leakage. This is because there is a wide range of leakage performance on DMAs.

Table 4: $\quad$ Summary of NRW Assessments for DMAs.

\begin{tabular}{lccc}
\hline \multicolumn{1}{c}{ Area } & Assessment of NRW (\%) & $\begin{array}{c}\text { Estimate of Real Losses } \\
\text { Based on National } \\
\text { CARL Normalized } \\
\text { using NRW Ratio (\%) }\end{array}$ \\
\hline Al-Sha'ab & 49 & Night Flow & 12 \\
Al-Rihab & 21 & - & 5 \\
Al-Qadsiya & 35 & 18 & 9 \\
Al-Riggae & 11 & 9 & 3 \\
Al-Shuhada & 5 & 2 & 1 \\
Al-Hadiya & 15 & 1 & 4 \\
\hline
\end{tabular}

\section{Conclusions}

A preliminary system-water balance has been carried out using available reported data. This water balance indicates that the real water leakage loss in the system is about $5 \%$. There are wide confidence limits on these assessments, which can be interpreted as that the real loss can be as high as $13 \%$ and as low as $0 \%$ in individual controlled and metered areas.

An attempt was carried out to validate real leakage levels by investigating night flows and water balances on six "district metered areas” (DMAs), namely, Al-Sha’ab Al-Sahili, Al-Rihab, Al-Qadsiya, Al-Riggae, Al-Shuhada and AlHadiya. Based on the national average of real losses normalized by the ratio of the local mass balance discrepancy to the national average, the estimates of real loss (leakage) ranged from 1 to $12 \%$.

More detailed leakage detection surveys and pressure drop tests were carried out on each DMA. The leakage detection survey field work indicated that there was little detectable real leakage except for Al-Qadsiya DMA. Almost all the leakages found were at the consumer connection.

During the investigation a number of issues were found related to customer metering. These included: poor installation details; pumps on the supply pipe affecting meter readings; effect of wear on minimum recorded flows; damaged 
meters; and choice of meter class affecting meter accuracy. The combined effect of these issues means that there could be significant meter under registration.

The non-revenue water loss of the whole system input volume includes apparent losses such as unbilled authorized and unauthorized use, operational use and meter under registration. It was estimated that authorized non-revenue water is about 6\%. In the six DMA survey the non-revenue water percentage was found in the range from 5 to $49 \%$. Unfortunately because of the lack of current and past consumer meter readings (revenue records) the analysis was only possible by generalizing limited sample averages to each DMA that deteriorated the level of confidence in the results.

\section{Recommendations}

\subsection{System water balance}

A computer program should be developed by the customer services of MEW to analyze meter billing records to produce consumption volumes on a regular (monthly) basis, according to household and non-household uses (including governmental). The system water balance should be broken down into balances over a number of zones so as to improve confidence and identify any potential losses between production points and these zones, and between the distribution points within these zones and DMAs.

\subsection{DMA monitoring}

A program of continuous logging of DMA meters arranged over 15 min periods should be established where the information is stored in a database. A leakage monitoring software should be used to carry out weekly monitoring of water balance, night flow assessments and data quality.

\subsection{Metering issues}

An investigation should be carried out on a number of sites to investigate the potential and level of meter under registration due to the exceeding Qmax. This will involve:

- Developing a methodology for logging the period in which a pump is running but a meter is not recording the flow.

- Assessment of the likely volume lost using either a test rig of a typical installation or an estimate from the pump duty.

- Estimating the number of meters where this is occurring.

- More accurate estimates of the level of meter under registration should be carried out. This would involve:

- Carrying out logging at shorter time intervals (less than $30 \mathrm{~min}$ ) to establish the frequency distribution of flow rate more accurately.

- Analyzing the frequency distribution of flows by banding the distributions by average consumption to derive average distribution curves. 
- Applying meter calibration curves (preferably involving a sample of existing worn meters) to these distribution curves to estimate the meter under registration by category.

- Surveys of the distribution of the current meter stock, including average consumption, pumped/not pumped, number of stories fed, and age (total volume passed), Qstart, etc. so that the total meter system under registration can be estimated.

An investigation should be carried out into the suitability of flow restrictors in limiting the flow of pumped installations to below Qmax. This should involve a test rig evaluation initially followed by site trials in a number of typical installations. Further surveys should be carried out to evaluate the deterioration of Qstart with meter duty and whether this is a function of being pumped or not.

Investigations are carried out to establish whether meter deterioration due to wear can be retarded by the installation of a filter or improved strainer. A revenue meter policy should be developed covering:

- Meter selection (cold water, hot water, class).

- Meter sizing.

- Meter installation details (covering orientation, strainers, restrictors, bends etc.).

- Allowable pump arrangements.

- Meter replacement program.

- Multiple occupancy situations.

\subsection{Pumped systems}

A number of short interval (i.e., $1 \mathrm{~s}$ ) pressure logging exercises should be carried out to investigate the impact of pumped systems on pressure transients within the distribution network. A code detailing allowable and approved pumping arrangements should be developed, publicized, and enforced.

\subsection{Service failures}

An investigation should be carried out to confirm the extent and type of service pipe failures. A study should be commissioned to develop recommendations for changes in policy and practice with respect to material selection, procurement, and laying procedures with the intention of reducing this failure rate.

\section{Acknowledgement}

The Hydrology Department of the Water Resources Division at the Kuwait Institute for Scientific Research (KISR) would like to express its appreciation to the Ministry of Electricity and Water (MEW) for their sponsoring and supporting of this study. 


\section{References}

[1] MEW. 2006. Ministry of Electricity and Water Statistical Year Book. Website http://www.mew.gov.kw/Default.aspx?pageId=508\&mid=244.

[2] Azrag, E.; J. Al-Kandari; K. Al-Fahad; B. Al-Salman; A. Bushehri and A. Al-Khalid. 2006. Estimation of Leakage from the Freshwater Network in Kuwait. Progress Report, Kuwait Institute for Scientific Research, Report No. KISR8467, Kuwait.

[3] Lambert A. O.; T. G. Brown; M. Takizawa and D. Weimer. 1999. A Review of Performance Indicators for Real Losses from Water Supply Systems. Journal of Water Supply: Research and Technology - AQUA 48(6):227-237.

[4] MEW. 2006. Ministry of Electricity and Water Statistical Year Book. Website http://www.mew.gov.kw/Default.aspx?pageId=508\&mid=244. 